\title{
Fat-free mass prediction equations for bioelectric impedance analysis compared to dual energy X-ray absorptiometry in obese adolescents: a validation study
}

Geesje H. Hofsteenge ${ }^{1 *}$, Mai JM Chinapaw ${ }^{2,3}$ and Peter JM Weijs ${ }^{1,2,4}$

\begin{abstract}
Background: In clinical practice, patient friendly methods to assess body composition in obese adolescents are needed. Therefore, the bioelectrical impedance analysis (BIA) related fat-free mass (FFM) prediction equations (FFM-BIA) were evaluated in obese adolescents (age 11-18 years) compared to FFM measured by dual-energy $x$-ray absorptiometry (FFM-DXA) and a new population specific FFM-BIA equation is developed.
\end{abstract}

Methods: After an overnight fast, the subjects attended the outpatient clinic. After measuring height and weight, a full body scan by dual-energy x-ray absorptiometry (DXA) and a BIA measurement was performed. Thirteen predictive FFM-BIA equations based on weight, height, age, resistance, reactance and/or impedance were systematically selected and compared to FFM-DXA. Accuracy of FFM-BIA equations was evaluated by the percentage adolescents predicted within $5 \%$ of FFM-DXA measured, the mean percentage difference between predicted and measured values (bias) and the Root Mean Squared prediction Error (RMSE). Multiple linear regression was conducted to develop a new BIA equation.

Results: Validation was based on 103 adolescents (60\% girls), age 14.5 (sd1.7) years, weight 94.1 (sd15.6) kg and FFM-DXA of $56.1(\mathrm{sd} 9.8) \mathrm{kg}$. The percentage accurate estimations varied between equations from 0 to $68 \%$; bias ranged from -29.3 to $+36.3 \%$ and RMSE ranged from 2.8 to $12.4 \mathrm{~kg}$. An alternative prediction equation was developed: $\mathrm{FFM}=0.527 * \mathrm{H}(\mathrm{cm})^{2} / \mathrm{Imp}+0.306 *$ weight $-1.862\left(\mathrm{R}^{2}=0.92\right.$, SEE $\left.=2.85 \mathrm{~kg}\right)$.

Percentage accurate prediction was $76 \%$.

Conclusions: Compared to DXA, the Gray equation underestimated the FFM with $0.4 \mathrm{~kg}(55.7 \pm 8.3)$, had an RMSE of $3.2 \mathrm{~kg}, 63 \%$ accurate prediction and the smallest bias of $(-0.1 \%)$. When split by sex, the Gray equation had the narrowest range in accurate predictions, bias, and RMSE. For the assessment of FFM with BIA, the Gray-FFM equation appears to be the most accurate, but $63 \%$ is still not at an acceptable accuracy level for obese adolescents. The new equation appears to be appropriate but await further validation. DXA measurement remains the method of choice for FFM in obese adolescents.

Trial registration: Netherlands Trial Register (ISRCTN27626398).

Keywords: Body composition, Accuracy, Obesity

\footnotetext{
* Correspondence: A.Hofsteenge@vumc.nl

${ }^{1}$ Department of Nutrition \& Dietetics, Internal Medicine, VU University

Medical Center, De Boelelaan 1117, 1081, HV, Amsterdam, The Netherlands

Full list of author information is available at the end of the article
} 


\section{Background}

The prevalence of obesity in adolescents is high and increasing [1, 2]. Accurate assessment of fat mass (FM) and fat-free mass (FFM) in obese adolescents is necessary for establishing reachable goals for healthy weight loss and evaluation of treatment. One of the main objectives of obesity management is to reduce FM and to preserve FFM during weight loss. Especially in adolescents FFM changes will occur, and therefore weight change is less informative. Body composition (FFM and FM) can be assessed by several techniques such as underwater weighing, total body potassium, deuterium dilution and dual energy X-ray absorptiometry (DXA). These methods are time-consuming, expensive; need trained operators and are hardly feasible in most dietetic settings [3, 4]. DXA is acknowledged as the standard [5] and most precise [6] method to assess body fat mass, although it can only be used in special settings and requires the use of a very low dose of radiation [7]. Unlike other methods, DXA measures three components of body composition - bone mineral content, fat tissue mass, and lean tissue mass - as well as regional fat distribution.

In contrast to DXA, bioelectrical impedance analysis (BIA) is a commonly used, safe and simple, portable, non-invasive, inexpensive technique that needs minimal operator training, making it appropriate for use in daily clinical practice. The BIA method is based on the conduction of electrical current in the body and differences in electrical conductivity between the fat and water components of the body. The electrical resistance and reactance together with body weight and height can reliably estimate body composition. But, the results of the BIA is highly dependent on which FFM-BIA equation is used. In order to assess FFM with BIA, several FFM-BIA equations have been developed. Only a few FFM equations have been developed for obese adolescents [8-10]. To the best of our knowledge no studies exist on validation of all available FFM equations in obese Caucasian adolescents. Because of their mean weight and BMI our study group was almost comparable with adults. This is the reason to include also BIA equations based on healthy and obese adults. As part of evidence-based practice, the aim of this study was to 1) examine the validity of published BIA-FFM equations, based on healthy and/or obese population (children and adults), for obese 11-18 year old adolescents using DXA as the reference method and 2) to develop a new FFM-BIA equation for obese adolescents.

\section{Methods}

Subjects

Adolescents were referred by their general practitioner or school doctor to the outpatient pediatric obesity clinic of the VU University Medical Center Amsterdam. At their first visit the paediatric-endocrinologist interviewed all adolescents concerning their medical history, weight development and ethnicity $[11,12]$. The physical examination included height, weight, waist circumference, blood pressure and pubertal Tanner stage [13].

Subjects were eligible when they met the following inclusion criteria: 1) age of 11-18 years; 2) obesity according to the definition of Cole et al. [14]. Cole et al. provide international cut off points for body mass index for overweight and obesity by sex in childhood (2-18 years), based on international data and linked to the widely accepted adult cut off points of a body mass index of 25 and $30 \mathrm{~kg} / \mathrm{m}^{2}$. Exclusion criteria were: not Dutch-speaking, obesity as a result of a known syndrome or organic cause (hypothyroidism), developmentally delayed, physical limitations (e.g. wheelchair dependent) and diagnosed type 2 diabetes mellitus. Subjects were measured between November 2006 and August 2008.

\section{Ethics}

The medical ethical committee of VU University Medical Center approved the study protocol. Adolescents, as well as their parents, gave written informed consent.

\section{Anthropometrics}

All measurements were performed using the same protocol. After an overnight fast, the subjects attended the outpatient clinic. Height was measured with an accuracy of $0.1 \mathrm{~cm}$ with an electronic stadiometer (KERN250D, De Grood Metaaltechniek, Nijmegen, Netherlands). Body weight (WT) was measured (in underwear) within $0.1 \mathrm{~kg}$ with a calibrated electronic flat scale (SECA861, Schinkel, Nieuwegein, Netherlands). Weight and height were used to calculate BMI (weight in kilograms divided by the square of height in meters). For the body mass index standard deviation score (BMIsds) reference data of Dutch children collected in 1997, were used (www.growthanalyser.org) and the sds, or z-score, calculated. The BMIsds indicates how many standard deviations a measurement is above or below the mean of the normal distribution.

\section{Dual energy $\mathbf{x}$-ray absorptiometry}

After measuring height and weight, a full body scan was performed by dual-energy x-ray absorptiometry (DXA; Hologic QDR4500-Delphi, software 12.3.3. S/N 45665, Tromp Medical, Castricum). DXA is based on the measurement of the attenuation of a collimated $x$-ray beam from a source with two energies passing through the body. Subjects (in the fasting state) were scanned for $10 \mathrm{~min}$ in underwear while lying in the supine position. The DXA method assessed, total body weight (WTdxa), 
fat mass (FM) and fat-free mass (FFM) defined as lean tissue mass including bone mineral content.

\section{Bioelectrical impedance analyzes (BIA)}

On the same morning as the DXA and also in the fasting state a BIA measurement was performed. Shoes and socks were removed, and the subjects were in a supine position. The BIA measurements were carried out on the non-dominant side of the subject, using a Hydra ECF/ICF Bio-Impedance Spectrum Analyzer, model 4200 (Xitron Technologies, San Diego, CA, USA). Four electrodes were placed on the hand and foot. For the wrist, one electrode was placed to bisect the ulnar hand, and the other electrode was placed just behind the middle finger. One of the ankle electrodes was placed to bisect the medial malleolus and the other was placed just behind the middle toe. The resistance and reactance measured at $50 \mathrm{kHz}$ were used in the evaluation of BIAFFM equations, obtained by the program Hydra Data Acquisition Utility.

\section{BIA-FFM equations}

PubMed was systematically searched (through November 2014) for publications on Mesh-derived keywords; Electric Impedance, Absorptiometry, Photon, body composition, equations and prediction in every possible combination. Applied limitations were 'English language', 'humans', not 'critical illness', and 'intensive care'. More references were obtained by screening reference lists of relevant publications. Equations were included when based on impedance or resistance data from BIA, and when the study was performed in a healthy or obese population mean age $>11$ years including both males and females. Exclusion criteria were: patients, insufficient information on body assessment method (e.g. FFM based on assumptions), only a specific ethnic group (other than Caucasian), small sample size $(n<50)$, only based on elderly ( $>60$ years), unusual variable in the fat free mass equation (e.g. skinfold, body density, deuterium dilution) and athletes.

\section{Statistics}

Subject characteristics (boys versus girls) were analyzed by independent samples T-test. For each participant, the FFM was predicted by the equations (FFM-BIA) and determined by DXA (FFM-DXA). The percentage of subjects with BIA-FFM predicted within $\pm 5 \%$ of FFM-DXA was considered as a measure of accuracy at the individual level. This limit was chosen as being consistent with technical measurement errors of $5 \%$ or less [9]. A predicted BIA-FFM below $95 \%$ of FFM-DXA was classified as underestimation and a prediction above $105 \%$ of FFM-DXA was classified as overestimation. The mean percentage difference between the predicted FFM-BIA and FFM-DXA was considered a measure of accuracy on a group level (bias). Also, the maximum values found for negative error (underestimation) and positive error (overestimation) were determined. The root mean squared prediction error (RMSE) was used to indicate how well the equation predicted in our dataset. The RMSE is calculated based on the difference between the BIA predicted value and the DXA reference value, all individual differences squared, taken the mean of the squared differences, and subsequently the root of the mean value [15]. The most accurate equation was defined as follows: the highest level of accurate predictions, with the smallest difference between boys and girls (to find the best fitting equation for both sexes), with the smallest bias, and the smallest RMSE. For the development of a new BIA equation the DEXA-derived FFM was applied as the criterion for the development of a new prediction through multiple regression analysis. The following potentially influencing variables were used: body weight, age, body height, BMI, RI, ZI, R, Z, X, sex (coded as female $=0$ and male $=1$ ), and Tanner's stages [16]. Additionally we have conducted an evaluation of accuracy of the best performing BIA approach as concluded from the baseline evaluation. For 73 subjects ( 25 boys, 48 girls) we had matching six months follow-up BIA and DXA measurements as part of a weight loss trial [17]. In this way, it was possible to evaluate the values for monitoring the subjects in time. Data were analyzed using SPSS 20.0 and RMSE with Excel.

\section{Results}

A total of 125 adolescents participated in this study. 22 adolescents were excluded because of overweight $(n=10)$, due to a body weight higher than allowed for the DXA $(>125 \mathrm{~kg})(n=4)$ or missing data because of defective equipment (BIA) $(n=8)$. Table 1 shows subject characteristics of the 103 (61 girls, 42 boys) adolescents by sex.

A total of 55 studies were retrieved examining BIAFFM equations. Our first search provided 24 citations. Another 31 citations were obtained by screening reference lists of relevant publications. Forty-two papers were excluded due to the mean age $<11$ year $(n=16)$; one gender $(n=4)$; patients $(n=6)$, insufficient information $(n=6)$; specific ethnic group $(n=2)$; small sample size $(n<50)(n=1)$; only based on elderly $(>60$ y) $(n=1)$; unusual variable (e.g. body density, deuterium dilution) ( $n$ =3); non-standard (standard $=50 \mathrm{kH})$ method $(1 \mathrm{MHz})$ or no hand to foot measurement $(n=3)$. Of the thirteen included studies (see Table 2) we selected the best equation per study based on explained variance in regression analysis. Five equations were based on only children $<19$ y $[8,9,18-20]$, only two equations were based on adolescents in the age range of $10-18$ years $[9,19]$. One 
Table 1 Subject characteristics

\begin{tabular}{llll}
\hline & Total $(n=103)$ & $\begin{array}{l}\text { Girls }(n=61) \\
\text { Mean }(\mathrm{sd})\end{array}$ & $\begin{array}{l}\text { Boys }(n=42) \\
\text { Mean }(\mathrm{sd})\end{array}$ \\
\hline Age, $\mathrm{y}$ & $14.4(1.7)$ & $14.7(1.7)$ & $14.1(1.7)$ \\
Height, $\mathrm{m}$ & $1.66(0.09)$ & $1.64(0.06)$ & $1.69(0.12)$ \\
Weight, $\mathrm{kg}$ & $94.3(15.7)$ & $94.3(14.0)$ & $94.2(18.0)$ \\
Waist circumference, $\mathrm{cm}$ & $109.0(11.1)$ & $108.4(11.1)$ & $109.7(11.2)$ \\
BMI (kg/m $\left.{ }^{2}\right)$ & $33.9(4.1)$ & $34.8(4.2)$ & $32.7(3.5)$ \\
BMI SDS & $2.98(0.34)$ & $2.94(0.35)$ & $3.05(0.32)$ \\
Tanner stage, $\mathrm{n}^{\mathrm{b}}$ & & & \\
Pre-pubertal (stage 1) & 32 & 10 & 22 \\
Pubertal (stage $\geq 2)$ & 65 & 50 & 15 \\
BIA & & & \\
-Resistance, $\Omega$ & $505.2(54.1)$ & $508.8(49.2)$ & $500.0(60.7)$ \\
-Reactance, $\Omega$ & $62.6(7.7)$ & $63.9(7.7)$ & $60.7(7.5)$ \\
-Impedance, $(\mathrm{Z})$ & $509.1(54.3)$ & $512.8(49.6)$ & $503.7(60.8)$ \\
-Fat-free mass, kg & $57.8(10.1)$ & $55.9(7.4)$ & $60.4(12.7)$ \\
DXA & & & \\
-Fat-free mass, kg & $56.1(9.8)$ & $54.7(7.1)$ & $58.1(12.5)$ \\
\hline
\end{tabular}

${ }^{a}$ Fat-free mass is supplied by Hydra ECF/ICF Bio-Impedance Spectrum Analyzer ${ }^{\mathrm{b}}$ For Tanner stage missing values were 1 for girls and 5 for boys

equation was based on obese adolescents only [9] and two studies were based on Dutch adolescents $[18,21]$.

The FFM average for the entire study group measured by DXA was $56.1 \mathrm{sd} 9.8 \mathrm{~kg}$. Table 3 provides the FFM data as mean measured FFM in $\mathrm{kg}$, the percentage of accurate under- and overestimation, the percentage bias, the maximum values found for negative error (underestimation) and positive error (overestimation) and the RMSE in $\mathrm{kg}$. The percentage accurate estimations varied between equations from 0 to $68 \%$. The bias for equations varied from $-21.5 \%$ to $+21.6 \%$ and RMSE varied from 2.9 to $13.5 \mathrm{~kg}$. Individual errors were much higher as shown by maximum negative and maximum positive error.

Figure 1 shows the percentage of accurate predictions (based on an FFM-BIA within $\pm 5 \%$ of FFMDXA), percentage bias, and RMSE for the total group of adolescents by sex. For the total group of adolescents the Deurenberg'90 equation had the smallest RMSE $(2.9 \mathrm{~kg}$ ), $68 \%$ accurate predictions (with $4 \%$ underprediction and $28 \%$ over-prediction) and a bias of $2.5 \%$. The Gray equation had an RMSE of $3.2 \mathrm{~kg}$, $63 \%$ accurate prediction (with $18 \%$ underprediction and $18 \%$ over prediction) and the smallest bias $(-0.1 \%)$. The Kyle equation had an RMSE of $3.1 \mathrm{~kg}$, $61 \%$ accurate prediction (16\% underprediction, $23 \%$ over prediction and a bias of $1.2 \%$ ). When split by sex, the Gray equation had the narrowest range in accurate predictions, bias, and RMSE.
Subjects were adolescents and therefore FFM measured at six months after baseline had increased by $1.49+2.72 \mathrm{~kg}$ as observed by DXA. The best performing BIA equation (the Gray equation) underestimated the FFM change with $(0.98+2.90 \mathrm{~kg} ; p=0.037)$.

\section{Development of new FFM-BIA equation for obese adolescents}

$\mathrm{H}(\mathrm{cm})^{2} / \mathrm{Imp}$ was identified as the strongest predictor of FFM $\left(R^{2}=0.82 ; P<0.0001\right)$. When both $\mathrm{H}(\mathrm{cm})^{2} / \mathrm{Imp}$ and bodyweight were included in the regression model, the explained variance $\left(R^{2}\right)$ was $92 \%$. Other variables did not further improve explained variance, which was consistently high for subgroups: sex $\left(R^{2}\right.$ girls 0.89 , boys 0.93$)$, puberty ( $R^{2}$ early 0.92 , late 0.89$)$. The new FFM-BIA equation was: $\mathrm{FFM}=0.527 * \mathrm{H}(\mathrm{cm})^{2} / \mathrm{Imp}+0.306 *$ weight -1.862 $(\mathrm{R} 2=0.92, \mathrm{SEE}=2.85)$. Accurate predictions within this study group was $76 \%$, however this equation awaits external validation.

\section{Discussion}

To our knowledge this is the first study evaluating all relevant available BIA-FFM equations for assessment of FFM in obese adolescents. We ranked BIA-FFM equations in the percentage of obese adolescents whose FFM was assessed within a reasonable range of error. The equations proposed by Deurenberg'90 et al. [21], Gray et al. [22], and Kyle et al. [23] were able to assess FFM in $61-68 \%$ of the obese adolescents within $5 \%$ of the DXA assessment. This study shows that for the assessment of FFM in obese adolescents, DXA and the BIAFFM equations are not interchangeable. Some BIA-FFM equations perform better than others, but all lack accuracy. The Gray equations performed best. Our new equation predicted FFM in $76 \%$ of the obese adolescents in our study group. However, the equation awaits external validation. There is no consensus regarding the level of error that is acceptable when measuring FFM. In theory the $2.5 \%$ cut-off value is clinically more appropriate than the $5 \%$ cut-off value, since an error of about $3 \mathrm{~kg}$ (see Table 2: $5 \%$ of FFM-DXA $(56,1 \mathrm{~kg})=3 \mathrm{~kg}$ ) appears quite large. In case a cut-off of $2.5 \%$ was used, the maximum accuracy level found was $35 \%$. However, in this study the cut-off level was mainly used to rank the available FFM-BIA equations from good to poor.

There is a whole range of published FFM-BIA equations, although only three originally developed in obese adolescents [8-10]. However, all three failed to produce acceptable FFM values comparable to DXA when applied to our sample of obese adolescents. Therefore, in this study, other FFM-BIA equations were considered, both based on a larger range of children with respect to age as well as weight and BMIsds. In an earlier study on energy expenditure we showed that obese adolescents 
Table 2 Predictive equations for fat-free mass based on children and adolescents and/or adults with normal weight, both normal weight and obese and obese only

\begin{tabular}{|c|c|c|c|c|c|c|}
\hline \multirow[t]{2}{*}{ Author; reference (ref), BIA system } & \multirow[t]{2}{*}{$N($ Male), age range y $(n)$} & \multirow{2}{*}{$\begin{array}{l}\text { Age (y) } \\
\text { Mean (sd) }\end{array}$} & \multirow{2}{*}{$\begin{array}{l}\text { Height }(\mathrm{cm}) \\
\text { Mean }(\mathrm{sd})\end{array}$} & \multirow{2}{*}{$\begin{array}{l}\text { Weight }(\mathrm{kg}) \\
\text { Mean }(\mathrm{sd})\end{array}$} & \multirow[t]{2}{*}{ FFM predictive equations } & \multirow{2}{*}{$\begin{array}{l}\text { Statistics and } \\
\text { cross-validation }\end{array}$} \\
\hline & & & & & & \\
\hline \multicolumn{7}{|c|}{ Equations based on healthy non-obese children, adolescents and/or adults } \\
\hline \multirow[t]{2}{*}{$\begin{array}{l}\text { Deurenberg'91 [18] ref: underwater weighing; } \\
\text { BIA-101 (RJL) }\end{array}$} & $827(361 \mathrm{M}), 7-15 y(n=166)$ & $28(17)$ & $169.6(14.3)$ & $64.8(17.2)$ & $\begin{array}{l}\leq 15 \mathrm{y}: 0.406^{*} 10^{4 *}\left(\mathrm{H}(\mathrm{m})^{2} / \mathrm{Imp}\right)+0.360 \\
W+5.58 \mathrm{H}(\mathrm{m})+0.56 \mathrm{SEX}-6.48\end{array}$ & $R^{2}=0.97, S E E=1.68$ \\
\hline & $16-83 y(n=661)$ & & & & $\begin{array}{l}\geq 16 y: 0.340 * 10^{4} *\left(\mathrm{H}(\mathrm{m})^{2} / \mathrm{Imp}\right)+15.34 \mathrm{H}(\mathrm{m})+ \\
0.273 \mathrm{~W}-0.127 \mathrm{AGE}+4.56 \mathrm{SEX}-12.44\end{array}$ & $R^{2}=0.93, S E E=2.63$ \\
\hline \multirow{4}{*}{$\begin{array}{l}\text { Deurenberg'90 [21] ref: underwater weighing; } \\
\text { BIA101 (RJL) }\end{array}$} & 246 (130 M); 10-15y: 71 M & $12.8(1.5)$ & $159.0(1.2)$ & $47.2(11.8)$ & \multirow{4}{*}{$\begin{array}{l}0.438^{*} 10^{4 *}\left(\mathrm{H}(\mathrm{m})^{2} / \mathrm{R}\right)+0.308 \mathrm{~W}+1.6 \mathrm{SEX}+ \\
7.04 \mathrm{H}(\mathrm{m})-8.5\end{array}$} & \multirow[t]{4}{*}{$r=0.99, \mathrm{SEE}=2.39$} \\
\hline & $20 \mathrm{~F}$ & $10.7(1.0)$ & $144.1(7.7)$ & $35.0(6.5)$ & & \\
\hline & $16-25 y: 41 M$ & $21.6(2.8)$ & $183.2(6.3)$ & $73.1(5.9)$ & & \\
\hline & $75 \mathrm{~F}$ & $17.6(3.6)$ & $168.3(6.7)$ & $57.9(9.5)$ & & \\
\hline $\begin{array}{l}\text { Houtkooper [19] ref: deuterium dilution; BIA101 } \\
\text { (RJL) }\end{array}$ & $95(53$ M),10-14y & $12.3(1.2)$ & $153.6(10.6)$ & $47.0(11.3)$ & $0.61\left(H^{2} / R\right)+0.25 W+1.31$ & $\mathrm{R}^{2}=0.95, \mathrm{SEE}=2.1$ \\
\hline \multirow[t]{14}{*}{ Kyle [23] ref: DXA; BIA: Xitron4000b } & 343 (202 M); 22-94y, 20-29y; 21 M & & $178.7(6.8)$ & $75.2(9.8)$ & \multirow{14}{*}{$\begin{array}{l}-4.104+0.518\left(H^{2} / R\right)+0.231 W+0.130 \text { Reac }+ \\
\text { 4.229SEX }\end{array}$} & \multirow[t]{14}{*}{$r=0.986, \mathrm{SEE}=1.72$} \\
\hline & $22 \mathrm{~F}$ & & $165.4(4.0)$ & $61.7(6.0)$ & & \\
\hline & 30-39y; $77 \mathrm{M}$ & & $178.2(7.1)$ & $79.1(10.6)$ & & \\
\hline & $29 \mathrm{~F}$ & & $166.4(6.0)$ & $61.8(6.4)$ & & \\
\hline & $40-49 y 36$ M & & $177.3(7.3)$ & $81.5(8.1)$ & & \\
\hline & $13 \mathrm{~F}$ & & $164.0(6.7)$ & $63.1(9.9)$ & & \\
\hline & $50-59 y ; 15 M$ & & $176.1(4.9)$ & $82.4(10.5)$ & & \\
\hline & $11 \mathrm{~F}$ & & $163.7(5.3)$ & $67.1(11.7)$ & & \\
\hline & $60-69 y ; 11 \mathrm{M}$ & & $173.4(4.5)$ & $77.3(10.1)$ & & \\
\hline & $18 \mathrm{~F}$ & & $161.9(6.6)$ & $65.0(11.2)$ & & \\
\hline & 70-79y; $30 \mathrm{M}$ & & $174.0(6.5)$ & $75.5(9.6)$ & & \\
\hline & $22 \mathrm{~F}$ & & $160.5(6.2)$ & $65.1(11.6)$ & & \\
\hline & $>80 ; 12 \mathrm{M}$ & & $168.3(6.1)$ & $72.7(8.7)$ & & \\
\hline & $33 \mathrm{~F}$ & & $156.5(3.9)$ & $59.9(8.6)$ & & \\
\hline \multirow{4}{*}{$\begin{array}{l}\text { Suprasongsin [33] ref: Isotope dilution (H2180); } \\
\text { BIA (RJL) }\end{array}$} & $56(28 \mathrm{M}) ;$ age $8-26 y$ & & & & \multirow[t]{4}{*}{$0.524\left(H^{2} / R\right)+0.415 W-0.32$} & \multirow[t]{4}{*}{$R^{2}=0.96, S E E=2.8$} \\
\hline & 18 prepubertal & $10.6(0.3)$ & $142.1(2.3)$ & $39.6(2.7)$ & & \\
\hline & 16 pubertal & $13.7(0.3)$ & $164.7(2.0)$ & $54.2(2.1)$ & & \\
\hline & 8 adults & $22.0(0.7)$ & $170.4(3.1)$ & $67.3(3.6)$ & & \\
\hline \multicolumn{7}{|c|}{ Equations based on healthy non-obese and obese children, adolescents and adults } \\
\hline \multirow[t]{2}{*}{ Gray [22] ref: underwater weighing; BIA (RJL) } & 87 (25 M); 19-74y, M & 41 & $178(164-198)$ & $99.6(57.8-179.1)$ & M: $0.00139 H^{2}-0.0801 R+0.187 W+39.830$ & $R^{2}=0.97$ \\
\hline & $\mathrm{F}$ & 41 & $164(152-177)$ & $89(51.0-148.6)$ & $\begin{array}{l}F: 0.00151 H^{2}-0.0344 R+0.140 W-0.158 \\
A G E+20.387\end{array}$ & $R^{2}=0.92$ \\
\hline
\end{tabular}

Houtkooper [19] ref: deuterium dilution; BIA101 (RJ

$22 \mathrm{~F}$

$29 \mathrm{~F}$

$13 \mathrm{~F}$

$18 \mathrm{~F}$

$33 \mathrm{~F}$ 
Table 2 Predictive equations for fat-free mass based on children and adolescents and/or adults with normal weight, both normal weight and obese and obese only (Continued)

underwater weighing; BIA four

terminal impedance plethysmograph (RJL)

Scheafer [20] ref: $40 \mathrm{~K}$ spectrometry, BIA (Holtain Ltd)

Sun [35] ref :4-C model hydrostatic weighing, deuterium dilution and DXA; BIA RJL
Equations based on healthy obese children, adolescents and adults

Haroun [10] ref: 3 C model (deuterium, BODPOD 78 (30 M), 5-22y

and WT; BIA: Tanita BC-418 MA)

Horie [36] ref: ADP (BODPOD) and FourF-BIA (Quadscan)

Lazzer [9] ref: DXA; BIS (Human IM plus II)

Wabitsch [8] ref: Deuterium dilution (labeled water); BIA RJL
114 (47 M), 18-50y, M

$112(59 \mathrm{M}), 3.9-19.3 y$

1304; 12-94y, 412 white M

114 black M

622 white $F$

156 black F

$26.9(8.0) \quad 182.4(9.1) \quad 86.0(16.4)$

$27.0(6.4) \quad 166.3(8.3) \quad 61.8(10.4)$

$11.8(3.7) \quad 150.2(19.7) \quad 42.8(16.6)$

$41.9(20.1) \quad 174.3(11.1) \quad 75.6(16.2)$

$48.3(19.3) \quad 173.7(8.6) \quad 79.9(15.4)$

$42.4(19.5) \quad 162.9(8.1) \quad 65.4(15.6)$

$51.7(18.4) \quad 161.1(8.7) \quad 73.5(17.1)$

$12.0(3.4) \quad 152.4(16.7) \quad 65.1(20.6)$

$11.3(3.5) \quad 148.0(13.7) \quad 60.1(16.3)$

$38.5(11.7) \quad 152.8(25.1) \quad 174.8(8.2)$

119 (36 M): M, age 18-62y, F (preoperative gastric bypass patients)

58 (27 M), 10-17y, severely obese subjects

146 (68 M), 5-17y; obese white subjects

$\begin{array}{ll}158.7(6.9) & 0\end{array}$

$14.2(1.9) \quad 164.0(10.0) \quad 92.5(14.5)$

$12.7(3.0) \quad 158.5(15.7) \quad 74.1(22.3)$
$0.756\left(H^{2} / R\right)+0.110 W+0.107$ Reac $-5.463 \quad r=0.99, S E E=2.3$

$0.65\left(H^{2} / \mathrm{Imp}\right)+0.68 \mathrm{AGE}+0.15$

$R^{2}=0.975$, RMSE $=1.98$

$M \cdot-10.68+0.65\left(H^{2} / R\right)+0.26 W+0.02 R$

$\mathrm{R}^{2}=0.90, \mathrm{RMSE}=3.9$

$F:-9.53+0.69\left(H^{2} / R\right)+0.17 W+0.02 R$

$R=0.83$, SEE 2.9

$-2.211+1.115\left(H^{2} / \mathrm{mp}\right)$

$R^{2}=0.96, \mathrm{SEE}=2.31$

$W T-(23.25+0.13 \mathrm{AGE}+1 \mathrm{~W}+$

$0.09 \mathrm{R}-0.80 \mathrm{H})$

$0.87\left(\mathrm{H}^{2} / \mathrm{Imp}\right)+3.1$

$r=0.91$, RMSE $=2.7$

$\left(0.35\left(H^{2} / R\right)+0.27 A G E+0.14 W-0.12\right) / 0.732 \quad R^{2}=0.96, S E E=1.91$

$M$ male; $F$ fema; $T$ total (man and fema); BIA bioectrical impedance analysis; DXA dual-energy $\mathrm{x}$-ray absorptiometry; $W$ weight in $\mathrm{kg} ; H$ height in $\mathrm{cm} \cdot H(\mathrm{~m})$ height in meters; $A G E$ age in $\mathrm{y} \cdot R$ Resistance; Reac Reactance; Imp Impedance; FFM fat-free mass; SEX (M=1,F=0) 
Table 3 Evaluation of Fat-Free Mass predictive equations in 103 Dutch obese adolescents, based on bias, RMSE, and percentage accurate prediction, sorted by \% accurate prediction

\begin{tabular}{|c|c|c|c|c|c|c|c|c|c|}
\hline \multirow[t]{2}{*}{$\begin{array}{l}\text { REE predictive } \\
\text { equation }\end{array}$} & $\mathrm{FFM}^{\mathrm{a}}$ & SD & Accurate predictions ${ }^{b}$ & Under predictions ${ }^{c}$ & Over predictions $^{d}$ & Bias $^{e}$ & $\begin{array}{c}\text { Maximum } \\
\text { negative error }\end{array}$ & $\begin{array}{c}\text { Maximum } \\
\text { positive error }\end{array}$ & RMSE $^{h}$ \\
\hline & $\mathrm{Kg} / \mathrm{d}$ & & $\%$ & $\%$ & $\%$ & $\%$ & $\%$ & $\%$ & $\mathrm{~kg}$ \\
\hline FFM-DXA & 56.1 & 9.8 & & & & & & & \\
\hline Deurenberg'90 [21] & 57.1 & 9.2 & 68.0 & 4.9 & 27.2 & 2.2 & -14.0 & 12.6 & 2.8 \\
\hline Gray [22] & 55.7 & 8.3 & 63.1 & 18.4 & 18.4 & -0.1 & -16.4 & 12.0 & 3.2 \\
\hline Kyle [23] & 56.4 & 8.4 & 61.2 & 15.5 & 23.3 & 1.2 & -10.3 & 17.2 & 3.1 \\
\hline Lukaski [34] & 53.7 & 8.5 & 54.4 & 39.8 & 5.8 & -3.8 & -17.3 & 11.0 & 3.9 \\
\hline Sun [35] & 57.1 & 9.6 & 49.5 & 16.5 & 34.0 & 2.2 & -11.2 & 18.8 & 3.8 \\
\hline Houtkooper [19] & 58.9 & 9.4 & 44.7 & 2.9 & 52.4 & 5.4 & -12.8 & 19.2 & 4.0 \\
\hline Deurenberg'91 [18] & 58.8 & 9.3 & 40.8 & 2.9 & 56.3 & 5.3 & -10.7 & 17.8 & 3.9 \\
\hline Haroun [10] & 59.5 & 10.9 & 35.9 & 7.8 & 56.3 & 6.2 & -13.0 & 29.7 & 5.7 \\
\hline Lazzer [9] & 51.2 & 8.5 & 28.2 & 69.9 & 1.9 & -8.3 & -23.2 & 9.0 & 6.4 \\
\hline Horie & 62.5 & 9.5 & 17.5 & 1.0 & 81.6 & 12.0 & -5.4 & 29.7 & 7.4 \\
\hline Wabitsch $[8,36]$ & 49.8 & 7.6 & 7.8 & 92.2 & 0.0 & -10.7 & -25.1 & 3.0 & 7.1 \\
\hline Schaefer [20] & 45.9 & 6.8 & 1.9 & 98.1 & 0.0 & -17.6 & -29.3 & -0.7 & 11.0 \\
\hline Suprasongsin [33] & 68.0 & 11.0 & 1.0 & 0.0 & 99.0 & 21.6 & 0.1 & 36.2 & 12.4 \\
\hline
\end{tabular}

${ }^{\mathrm{a} A s}$ measured

${ }^{\mathrm{b}}$ The percentage of subjects predicted by this predictive equation within $5 \%$ of the measured value

${ }^{\mathrm{c}}$ The percentage of subjects predicted by this predictive equation $<5 \%$ of the measured value

${ }^{d}$ The percentage of subjects predicted by this predictive equation $>5 \%$ of the measured value

${ }^{\mathrm{e}}$ Mean percentage error between predictive equation and the measured value

${ }^{\mathrm{f}}$ The largest underprediction that was found with this predictive equation as a percentage of the measured value

${ }^{9}$ The largest over prediction that was found with this predictive equation as a percentage of the measured value

${ }^{h_{R}}$ oot mean squared prediction error

have such stature and body mass that equations relevant for energy expenditure should rather be based on the 18+ category and not the normal $12-18$ year age range [24]. In fact, the Gray equation is developed in adults $(25 \mathrm{~m}, 62 \mathrm{f})$, with BMI varying from 19.6 tot $53.3 \mathrm{~kg} / \mathrm{m} 2$ and percent body fat from 8.8 tot $59 \%$. Compared to DXA in our study, the BIA algorithm that is part of the devices overestimated FFM in obese children and adolescents $[9,25]$. In healthy adult persons, the assumption is that $73.2 \%$ of the lean body mass consists of total body water [26]. Wells et al. found that in children (aged 4-23 y) the FFM hydration is higher (mean $75 \%$ ), and differed by age and sex [27]. In obese, the hydration of the lean body mass is also great er than $73.2 \%$. This increase in hydration in obese compared with non-obese individuals averaged $1 \%$ and reached $2 \%$ in extreme obesity [28]. So both, childhood and obesity could cause an overestimation of FFM, which in turn could underestimate FM. As far as we known, all selected developed FFM equations (see Table 2) are based on the assumption of the hydration factor of $73.2 \%$. So far, it is unclear whether FFM equations based on adults could be adapted for use in children by correction factor for hydration.
DXA is still the gold standard to measure body composition [29]. The current evaluation, in line with others $[25,30]$, neglects measurement error by DXA methodology [31] and ascribes all error, being the deviation between BIA and DXA, to the BIA methodology. Measurement error in FM (\%) can also result from inaccurate detection of FM in the trunk region or variation in tissue thickness [28]. Alternatively, an individual subject may have an overestimation of FFM by DXA and at the same time an underestimation by BIA-FFM [32]. Strengths of this study include the use of DXA, a robust and wellaccepted measure [29] and the systematic literature search of FFM-BIA equations.

A limitation of the study is that the interpretation is not applicable to other BIA and DXA devices or software. Besides this our DXA had a limit of $125 \mathrm{~kg}$. Larger individuals can currently be measured depending on the weight capacity and scanning area of the instrumentation. It is unknown whether our results can be extrapolated to the most obese adolescents. The new equation awaits external validation, as this was not possible in the present study due to the small sample. 


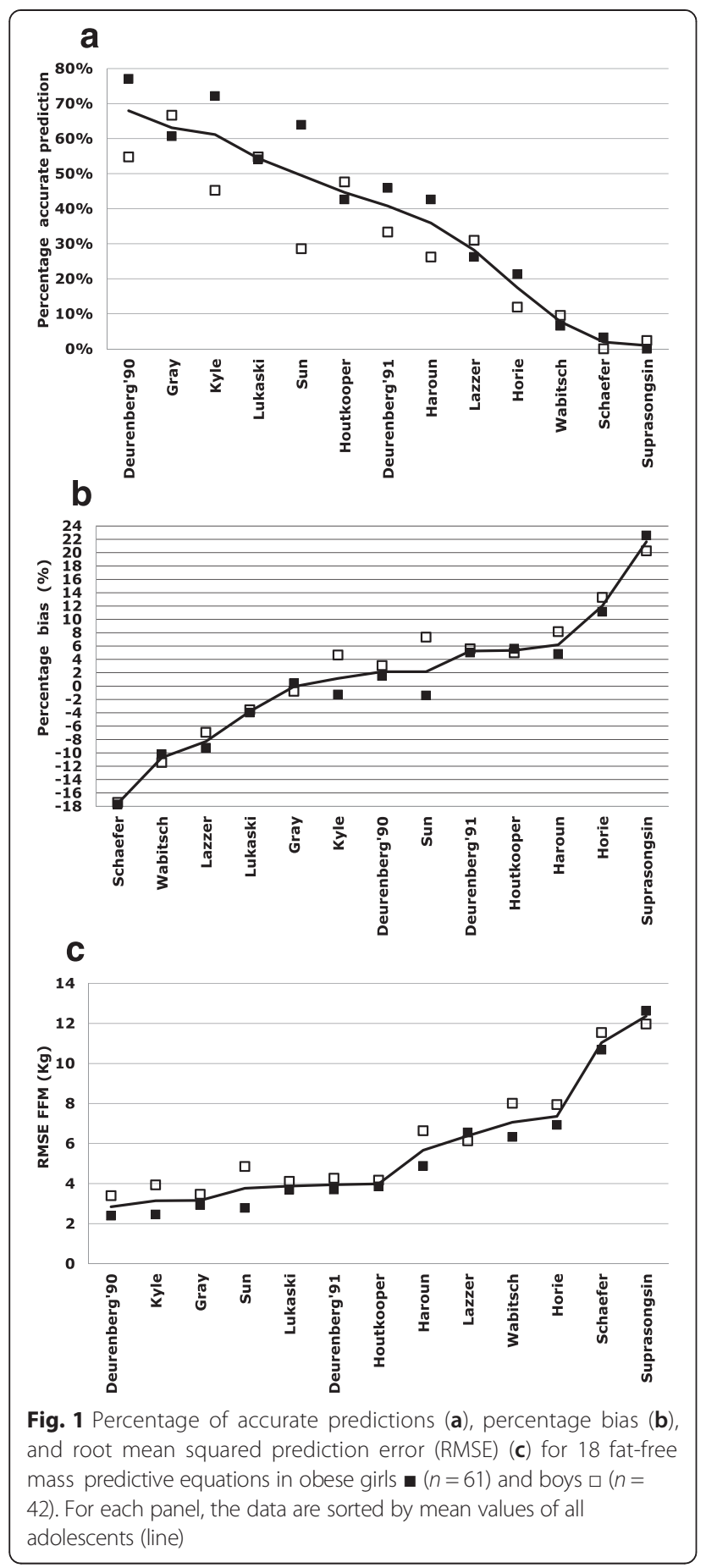

\section{Conclusions}

In conclusion, the present study shows that DXA and BIA-FFM equations are not interchangeable for the assessment of FFM in obese adolescents. There is a wide variation in the accuracy of predictive equations for FFM in obese adolescents. Compared to DXA, FFM of two out of three adolescents was accurately predicted using the Gray equation based on weight, height, age, sex, and resistance index.

\section{Ethical approval}

This study was approved by the ethical committee for human studies of the VU University Medical Center Amsterdam. The adolescents, as well as their parents, gave written informed consent.

\section{Abbreviations}

BIA: Bioelectrical impedance analysis; DXA: Dual energy x-ray absorptiometry; FFM: Fat free mass; FM: Fat mass; FFM-BIA: FFM calculated by BIA equation; FFM-DXA: FFM measured by dual energy x-ray absorptiometry; BMlsds: Body Mass Index standard deviation score; RMSE: Root Mean Squared prediction error.

\section{Competing interests}

The authors declare that they have no competing interests.

\section{Authors' contributions}

GH and PW participated in the design of the study; GH performed the statistical analysis; GH, PW, MC draft the manuscript; GH had primary responsibility for the final content. All authors read and approved the final manuscript.

\section{Acknowledgements}

The authors are grateful to the adolescents who participated in this study and their parents. We thank HA Delemarre-van de Waal t for her dedication to paediatric research and the opportunity to conduct this project. We also thank the Department Radiology of the VU University Medical Center in Amsterdam for their kind assistance during the study.

\section{Financial Support}

This study is funded by The Netherlands Organization for Health Research and Development (ZONMW) (no: 50-50110-98-255). The funding organization was not involved in the design and conduct of the study; nor were they involved in the collection, management, analysis, and interpretation of the data. Finally, the funding organization was not involved in the preparation, review or approval of the manuscript.

\section{Author details}

'Department of Nutrition \& Dietetics, Internal Medicine, VU University Medical Center, De Boelelaan 1117, 1081, HV, Amsterdam, The Netherlands. ${ }^{2}$ EMGO Institute for Health and Care Research, VU University Medical Center, Amsterdam, The Netherlands. ${ }^{3}$ Department of Public and Occupational Health, VU University Medical Center, Amsterdam, The Netherlands. ${ }^{4}$ Department of Nutrition \& Dietetics, Amsterdam University of Applied Sciences, Amsterdam, The Netherlands.

Received: 12 January 2015 Accepted: 6 October 2015 Published online: 15 October 2015

\section{References}

1. Schokker DF, Visscher TLS, Nooyens ACJ, van Baak MA, Seidell JC. Prevalence of overweight and obesity in the Netherlands. Obes Rev. 2007;8:101-8.

2. van den Hurk K, van Dommelen P, van Buuren S, Verkerk PH, Hirasing RA. Prevalence of overweight and obesity in the Netherlands in 2003, compared to 1980 and 1997. Arch Dis Child. 2007;92:992-5.

3. De Lorenzo A, Bertini I, Candeloro N, lacopino L, Andreoli A, Van Loan MD. Comparison of different techniques to measure body composition in moderately active adolescents. Br J Sports Med. 1998;32:215-9.

4. Demerath EW, Guo SS, Chumlea WC, Towne B, Roche AF, Siervogel RM. Comparison of percent body fat estimates using air displacement plethysmography and hydrodensitometry in adults and children. Int J Obes. 2002;26:389-97.

5. Dezenberg CV, Nagy TR, Gower BA, Johnson R, Goran Ml. Predicting body composition from anthropometry in pre-adolescent children. Int J Obes. 1999;23:253-9.

6. Fusch C, Slotboom J, Fuehrer U, Schumacher R, Keisker A, Zimmermann W, et al. Neonatal body composition: dual-energy $\mathrm{X}$-ray absorptiometry, 
magnetic resonance imaging, and three-dimensional chemical shift imaging versus chemical analysis in piglets. Pediatr Res. 1999;46:465-73.

7. Pietrobelli A, Wang Z, Heymsfield SB. Techniques used in measuring human body composition. Curr Opin Clin Nutr Metab Care. 1998;1:439-48.

8. Wabitsch M, Braun U, Heinze E, Muche R, Mayer $H$, Teller W, et al. Body composition in 5-18-y-old obese children and adolescents before and after weight reduction as assessed by deuterium dilution and bioelectrical impedance analysis. Am J Clin Nutr. 1996;64:1-6.

9. Lazzer S, Bedogni G, Agosti F, De CA, Mornati D, Sartorio A. Comparison of dual-energy X-ray absorptiometry, air displacement plethysmography and bioelectrical impedance analysis for the assessment of body composition in severely obese Caucasian children and adolescents. Br J Nutr. 2008;100:918-24.

10. Haroun D, Croker H, Viner RM, Williams JE, Darch TS, Fewtrell MS, et al. Validation of BIA in obese children and adolescents and re-evaluation in a longitudinal study. Obesity. 2009;17:2245-50.

11. Statistics Netherlands. Standaarddefinitie allochtonen. Hoe doet het CBS dat nou? 10 ed. Voorburg, The Netherlands. 2000. p. 24-5.

12. Hofsteenge GH, Chinapaw MJM, Weijs PJM, van Tulder MW, Delemarre-van de Waal HA. Go4it; study design of a randomised controlled trial and economic evaluation of a multidisciplinary group intervention for obese adolescents for prevention of diabetes mellitus type 2. BMC Public Health. 2008:8:410.

13. Tanner JM. Growth and maturation during adolescence. Nutr Rev. 1981;39(2):43-55.

14. Cole TJ, Bellizzi MC, Flegal KM, Dietz WH. Establishing a standard definition for child overweight and obesity worldwide: international survey. Br Med J. 2000;320:1240-3.

15. Sheiner LB, Beal SL. Some suggestions for measuring predictive performance. J Pharmacokinet Biop. 1981:9:503-12.

16. Wang L, Sai-chuen Hui S, Heung-sang Wong S. Validity of bioelectrical impedance measurement in predicting fat-free mass of Chinese children and adolescents. Med Sci Monit. 2014;20:2298-310.

17. Hofsteenge GH, Chinapaw MJM, Delemarre-van de Waal HA, Weijs PJM. Long-term effect of the Go4it group treatment for obese adolescents: A randomised controlled trial. Clinical Nutrition. 2014;33(3):385-91.

18. Deurenberg P, van der Kooy K, Leenen R, Weststrate JA, Seidell JC. Sex and age specific prediction formulas for estimating body composition from bioelectrical impedance: a cross-validation study. Int J Obes. 1991;15:17-25.

19. Houtkooper LB, Going SB, Lohman TG, Roche AF, Van LM. Bioelectrical impedance estimation of fat-free body mass in children and youth: a crossvalidation study. J Appl Physiol. 1992;72:366-73.

20. Schaefer F, Georgi M, Zieger A, Scharer K. Usefulness of bioelectric impedance and skinfold measurements in predicting fat-free mass derived from total-body potassium in children. Pediatr Res. 1994;35:617-24.

21. Deurenberg P, Kusters CS, Smit HE. Assessment of body composition by bioelectrical impedance in children and young adults is strongly agedependent. Eur J Clin Nutr. 1990;44:261-8.

22. Gray DS, Bray GA, Gemayel N, Kaplan K. Effect of obesity on bioelectrical impedance. Am J Clin Nutr. 1989:50:255-60.

23. Kyle UG, Genton L, Karsegard L, Slosman DO, Pichard C. Single prediction equation for bioelectrical impedance analysis in adults aged 20-94 years. Nutrition. 2001;17:248-53.

24. Hofsteenge GH, Chinapaw MJ, Delemarre-van de Waal HA, Weijs PJ. Validation of predictive equations for resting energy expenditure in obese adolescents. Am J Clin Nutr. 2010;91:1244-54.

25. Eisenkölbl J, Kartasurya M, Widhalm K. Underestimation of percentage fat mass measured by bioelectrical impedance analysis compared to dual energy X-ray absorptiometry method in obese children. Eur J Clin Nutr. 2001;55:423-9.

26. Pace $\mathrm{N}$, Rathbun E. The body water and chemically combined nitrogen content in relation to fat content. J Biol Chem. 1945;158:685-91.

27. Wells JCK, Williams JE, Chomtho S, Darch T, Grijalva-Eternod C, Kennedy K, et al. Pediatric reference data for lean tissue properties: density and hydration from age 5 to 20 y. Am J Clin Nutr. 2010;91:610-8.

28. Wells JCK, Fewtrell MS, Williams JE, Haroun D, Lawson MS, Cole TJ. Body composition in normal weight, overweight and obese children: matched case-control analyses of total and regional tissue masses, and body composition trends in relation to relative weight. Int J Obes (Lond). 2006;30:1506-13.

29. Lohman TG. Advances in body composition assessment. Springfield, IL: Human Kinetics; 1992. p. 22.
30. Okasora K, Takaya R, Tokuda M, Fukunaga Y, Oguni T, Tanaka H, et al. Comparison of bioelectrical impedance analysis and dual energy $X$-ray absorptiometry for assessment of body composition in children. Pediatr Int. 1999;41:121-5.

31. Schoeller DA, Tylavsky FA, Baer DJ, Chumlea WC, Earthman CP, Fuerst T, et al. QDR 4500A dual-energy X-ray absorptiometer underestimates fat mass in comparison with criterion methods in adults. Am J Clin Nutr. 2005;81:1018-25.

32. Houtkooper LB, Lohman TG, Going SB, Howell WH. Why bioelectrical impedance analysis should be used for estimating adiposity. Am J Clin Nutr. 1996;64:S436-48.

33. Suprasongsin C, Kalhan S, Arslanian S. Determination of body-composition in children and adolescents - validation of bioelectrical-impedance with isotope-dilution technique. J Pediatr Endocr Met. 1995:8:103-9.

34. Lukaski HC, Bolonchuk WW, Hall CB, Siders WA. Validation of tetrapolar bioelectrical impedance method to assess human-body composition. J Appl Phys. 1986;60:1327-32

35. Sun SS, Chumlea WC, Heymsfield SB, Lukaski HC, Schoeller D, Friedl K, et al. Development of bioelectrical impedance analysis prediction equations for body composition with the use of a multicomponent model for use in epidemiologic surveys. Am J Clin Nutr. 2003;77:331-40.

36. Horie LM, Barbosa-Silva MCG, Torrinhas RS, Tulio de Melo M, Cecconello I, Waitzberg DL. New body fat prediction equations for severely obese patients. Clin Nutr. 2008;27:350-6.

\section{Submit your next manuscript to BioMed Central and take full advantage of:}

- Convenient online submission

- Thorough peer review

- No space constraints or color figure charges

- Immediate publication on acceptance

- Inclusion in PubMed, CAS, Scopus and Google Scholar

- Research which is freely available for redistribution 